\title{
Optimization of post weld heat treatment cycle of fiber laser welded bainitic steel
}

\author{
VSM Ramakrishna $\mathrm{R}^{\mathrm{a} *}$, and $J P$ Gautam $^{\mathrm{b}}$ \\ aMahatma Gandhi Institute of Technology, Hyderabad, India \\ bSEST, University of Hyderabad, Hyderabad, India
}

\begin{abstract}
Automobile industry has always been in look out for advanced materials that would account for greater crash resistance, high fatigue strength, optimum ductility and longer service life despite heavy mechanical loads applied on these engine components. These critical requirements are met through maintaining the complex microstructures and optimum phase constituents. The retention of microstructural constituents has always been a key parameter while fabricating these advanced automobile materials by fusion welding process. Carbide free bainitic steels are emerging out to be the candidate materials for automobile applications. Owing to their microstructure consisting fine bainitic ferrite laths that are interwoven with retained austenite in their lath boundaries. The fine Bainitic laths provide enough strength and the retained austenite phase facilitates the desired ductility. The current paper critically discusses the microstructural and microhardness variation across the zones during Fiber Laser welding of bainitic steel sheets. Keeping the phase transformations during welding in view, post weld heat treatments were undertaken. The welded steel was austenitized at $820^{\circ} \mathrm{C}$, rapidly cooled to $390{ }^{\circ} \mathrm{C}$, and soaked at different durations before furnace cooing. The microstructure variation and microhardness profiling were done at all these heat treatment conditions. Basing on the analyses, the heat treatment cycle has been optimized.
\end{abstract}

\section{Introduction}

Carbide free-bainitic steels are regarded to be candidate materials and gaining increasing interest in automotive sector. The combination of ultimate tensile strength and formability achieved in these steels with no need of complex heat treatments or thermomechanical processes represents their main advantage. The strength is mainly achieved by means of the very fine bainitic ferrite plates, where a soft retained austenite phase imbibed will control the levels of ductility achieved [1]. The TRIP effect exhibited by these steels facilitates the stability of retained austenite phase. This in turn results in attainment of required elongation in these steels. Of recent, ultrafine bainitic steel with desired combination of ultimate tensile strength and deformability was developed at TATA Steel Research and Development Group, Ijmuiden, Netherlands. The coils of these steel sheets were produced in a hot strip mill after employing accelerated cooling on the runout table (Ref. Fig.1). Temperatures lower than $400{ }^{\circ} \mathrm{C}$ was maintained to transform austenite. [2].

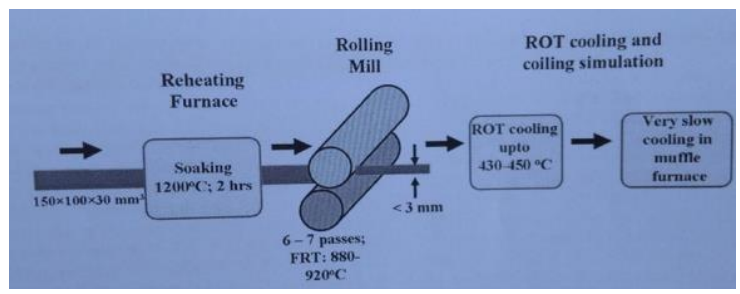

Fig. 1. Rolling method to produce bainitic steels for current study

During manufacturing of automotive components, welding is unavoidable [3]. Irrespective of what welding technique employed, the principal requirement of these bainitic steels is the retention of the much needed bainitic microstructure even after welding without producing wider heat affected zones [4]. Fiber Laser Welding is one among the established manufacturing techniques for automotive applications. In this process, the laser emits a coherent light. This is focused and reflected in similar way as light. The controlling parameters of size of focused spot are choice of lenses and distance from the base metal. The spot size can be regulated in the range of 75 micrometers to $0.75 \mathrm{~mm}$. the variation of this spot size 
is in accordance with the method to be undertaken. Smaller and sharply focused spot size is employed in welding and cutting, where as the larger spot size is applied while heat treating. The laser offers a source of concentrated energy for welding; however, there are only a few lasers in actual production use today [5]. The greater expenditure involved in producing high power density lasers has always been the significant bottleneck during laser welding. S the things stand, laser welding is in its infant state. However, there will be reduction in cost of welding and enhancement in the technology in near future. The contributory factors that influence the weldability aspects of Fiber Laser Welding are heat input during welding, power and of speed of laser beam. Among the aforementioned parameters, the change in speed is the important contributing parameter that dictates the phase transformations there by feasibility of welding [6]. The wide adoption of Fiber Laser Welding as the method of fabrication of steels was held up due to nonavailability of an appropriate fiber material. There have been few investigations exploring the possibility of using Laser Welding for fabrication of various steels. Post welding heat treatments are generally undertaken after welding to reduce the hardness or to impart the uniform mechanical properties in across the metal which is welded by reliving the stress during welding formed [7]. The current research has been undertaken keeping the following objectives in consideration: (i) to establish the feasibility of Fiber Laser Welding on bainitic steel plate of $3 \mathrm{~mm}$ thickness by conducting Plate-to-Plate (butt welding) experiments, (ii) to recommend the optimum post weld heat treatment cycle that would retain the parent microstructure and base material characteristics.

\section{Experimental Details}

Fiber Laser welding was conducted to obtain butt weld joint of the $3 \mathrm{~mm}$ thick bainitic steel plates. The laser welding Machine (Make: ARNOLD) is equipped with a Solid state Neodymium-Yttrium Aluminum Garnet (Nd: YAG) fiber as the source of laser and the beam. During welding process, the maximum beam power and the beam traverse speed of the machine were kept at $4 \mathrm{~kW}$ and $6 \mathrm{~m} / \mathrm{min}$ respectively. Beam focal length was maintained at $300 \mathrm{~mm}$, the beam spot diameter was set at $0.02 \mathrm{~mm}$. The Laser head angle was held at $90^{\circ}$ to the specimen surface. Argon gas was used with a purity of $99.999 \%$ and the flow rate was maintained at $10 \mathrm{~L} / \mathrm{min}$. The butt weld joint was obtained at 3.5 $\mathrm{kW}$ laser power and $2000 \mathrm{~mm} / \mathrm{min}$. beam speed as indicated in Fig. 2.

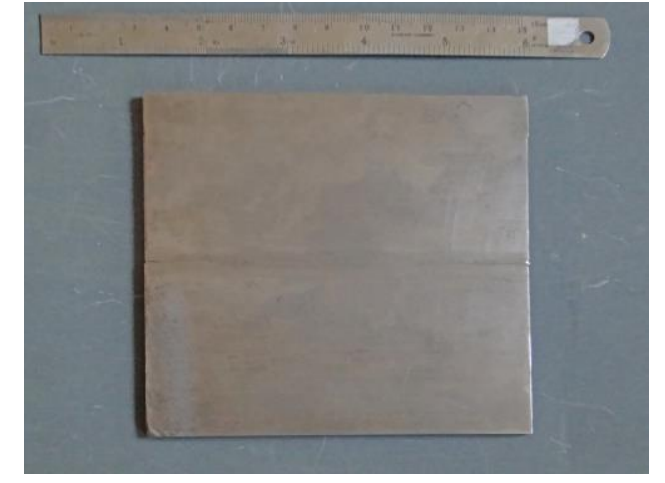

Fig. 2. Butt weld joint produced through Fiber Laser Welding

Post Weld Heat Treatments (PWHT) at different conditions of temperature, time and coiling mode were carried out in a protective atmosphere furnace. The Heat treatment cycles are indicated in Table 1. These heat treatment conditions have been designed keeping the bainitic transformation temperature for the steel taken into consideration. The temperatures and soaking durations were determined from the existing equations that calculate the $\mathrm{B}_{\mathrm{s}}$ (Bainitic start) and $\mathrm{B}_{\mathrm{f}}$ (Bainitic finish) temperatures.

Table 1. Post weld heat treatment cycles

\begin{tabular}{|c|c|c|c|c|}
\hline Cycle & $\mathrm{T}_{\text {aust }}{ }^{\mathrm{O}}{ }^{\mathrm{C}}$ & $\mathrm{t}_{\text {aust, }}$ min. & $\mathrm{T}_{\mathrm{Bs}},{ }^{\circ} \mathrm{C}$ & $\mathrm{t}_{\text {soak }}$, min. \\
\hline I & 820 & 10 & 390 & 60 \\
\hline II & 820 & 40 & 390 & 180 \\
\hline III & 820 & 60 & 390 & 300 \\
\hline
\end{tabular}

The samples after laser welding and post weld heat treatments were obtained from EDM wire cutting. Care has been exercised while obtaining these samples as they are desired to cover the base material, Heat Affected Zone, and weld zone. These samples were subjected to microscopy analysis and microhardness evaluation. The microstructural features were examined through optical, and Electron microscopy. The samples were initially polished with emery of increasing fineness (intermediate polishing). Later fine polishing was undertaken with $0.6 \mu \mathrm{m}$ and $0.1 \mu \mathrm{m}$ diamond pastes. Lepera reagent was used as an etchant to reveal the microstructural constituents. The Field Emission Gun enabled scanning electron microscope FIE make "NovananoSEM- 450"was used. Imaging was done under secondary electron mode at an accelerating voltage of $15-20 \mathrm{kV}$. TEM studies were carried out using a JEOL make JEM-21001 to investigate Bainite morphology and micro-chemical analysis. The operating voltage used was $200 \mathrm{kV}$. The sectioning was done using slow speed Isomet cutting machine. The slice after sectioning was mechanically polished up to thickness of 100 microns subsequently $3 \mathrm{~mm}$ discs were taken for further electro polishing using Struers Tenupole-5 twin jet electro polisher at 
$15 \mathrm{~V}$ and $250 \mathrm{~K}$. The t-EBSD (Transmission Electron Back Scattered Diffraction) analysis was undertaken with TEAM ${ }^{\mathrm{TM}}$ software. The samples of dimensions 4 $\mu \mathrm{mX} 6 \mu \mathrm{m}$ have been sliced. The thinner samples of the order $50 \mathrm{~nm}$ were prepared through Focused Ion Beam (FIB) Milling and placed. The images/patterns have been obtained for further analysis.

The Vickers microhardness indentations were performed at the mid-thickness of the weld cross section employing digital microhardness tester of Tinius Olsen FH make and 006 series model. A standard load of 1000 Gram was used for a dwell time of 15 seconds at a distance $0.15 \mathrm{~mm}$ between two successive indentations. The VHN was calculated with eq. $1[8]$

$$
V H N=\frac{P}{D^{2} /\left[2 \sin \left(136^{0} / 2\right)\right]}=1 \cdot 854 \frac{P}{D^{2}}
$$

VHN $=$ Vickers Hardness Number

$\mathrm{P}=$ Applied load in $\mathrm{kg}$

$\mathrm{D}=$ Average length of the Diagonals (d1 and d2).

\section{Results and Discussion}

In this section, the results of characterizations of base material, as welded and heat treated conditions are indicated. Discussions on the microscopy analysis and microshardness profiling are presented in detail.

\subsection{Characterization of base material}

The chemical composition of bainitic steel was analyzed through XRF and indicated in Table 2.

Table 2 Elemental analysis of Bainitic Steel

\begin{tabular}{|l|l|}
\hline Element & $\begin{array}{l}\text { Weight } \\
\%\end{array}$ \\
\hline Iron & $95-96$ \\
\hline Carbon & $0.3-0.4$ \\
\hline Manganese & $1.5-2.0$ \\
\hline Silicon & $1.3-1.6$ \\
\hline Others & $0.9-1.0$ \\
\hline
\end{tabular}

The optical and Scanning Electron micrographs are shown in Fig. 3. These micrographs reveal the existence of retained austenite and bainitic ferrite. The lath morphology of bainite phase has been observed.

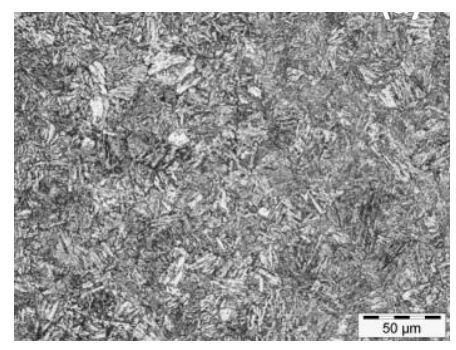

*Corresponding author: rvsmramakrishna_mme@mgit.ac.in

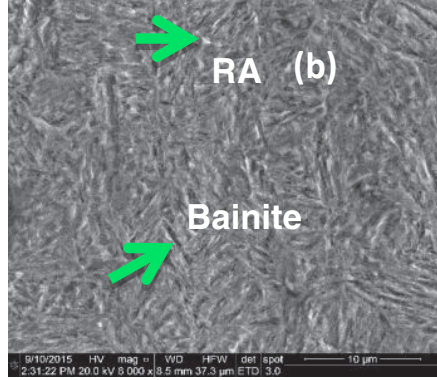

Fig. 3. (a) optical and (b) SEM images of as received base material (RA: retained austenite)

Further confirmatory analysis was done through Transmission Electron Microscopy and t-EBSD. The Fig. 4 indicates the TEM and t-EBSD images of the base material. The existence of bainite laths having interwoven retained austenite phase in the interlath boundaries is clearly evident from these images.

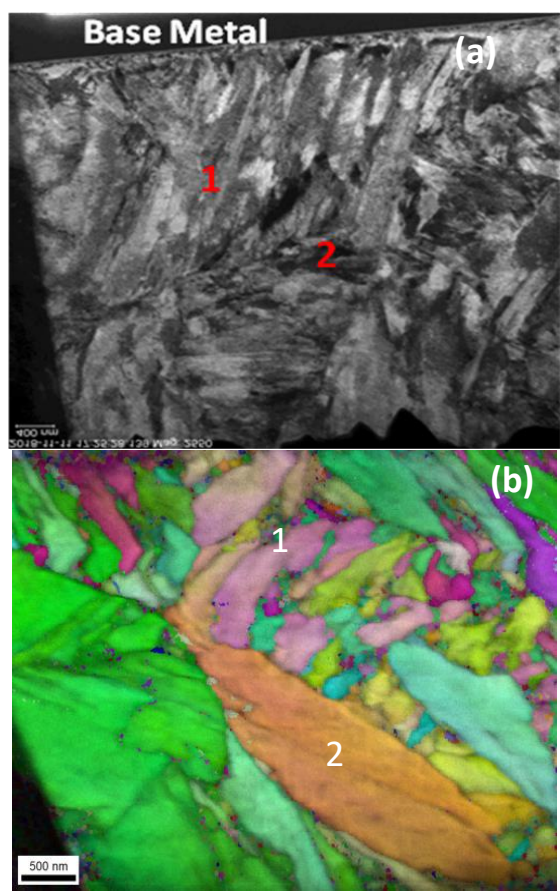

Fig. 4. (a) TEM and (b) t-EBSD images of as received base material (1: Retained austenite phase; 2 : bainite)

\subsection{Microscopy analysis of welds}

Clean and defect free butt joint was produced. Fig. 5 indicates the macroscopic view of three zones viz., base metal (BM), Heat Affected Zone (HAZ) and Weld zone (WZ) respectively.

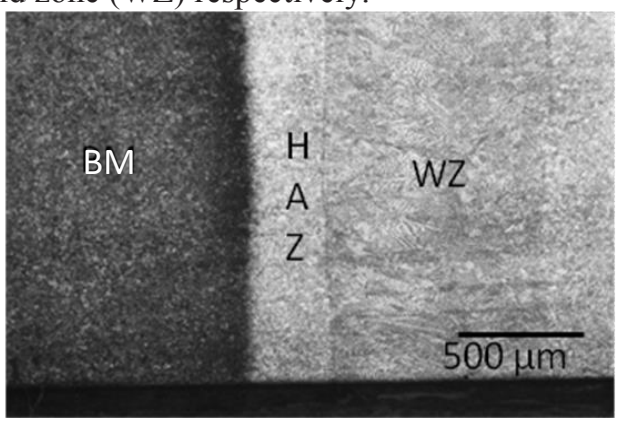

Fig. 5. Macroscopic view of zones after welding 
The optical and SEM images of the weld zone are shown in Fig.6. The optical micrograph clearly indicates the dendritic pattern in the weld zone. This is due mainly to the rapid cooling associated with welding. However, the SEM image indicates the martensite phase formation along with bainite phase. Ultrafast cooling of retained austenite phase has resulted into martensite phase in the weld zone.
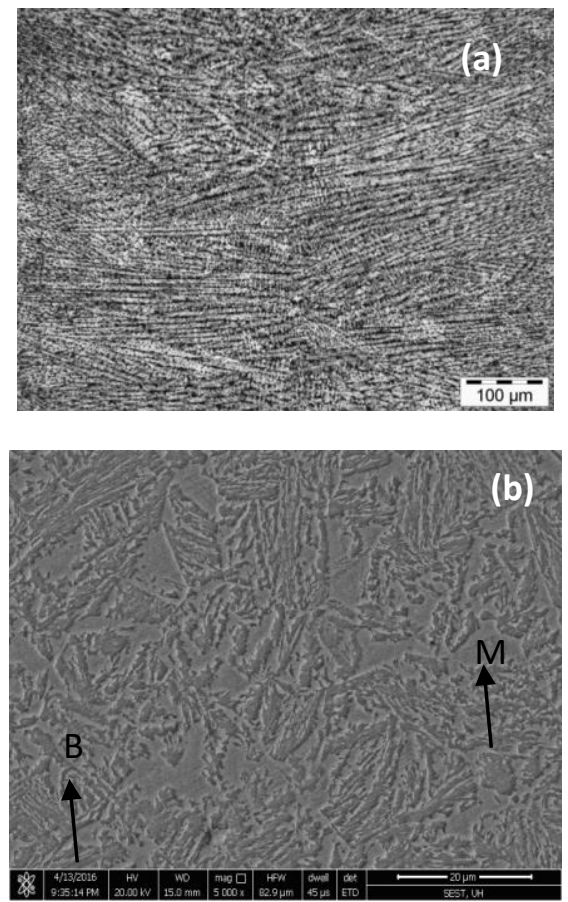

Fig. 6. (a) optical and (b) FESEM images of the weld zone after welding (M: martensite, B: bainite)

\subsection{Microhardness profiling in as welded condition}

The Vickers hardness profile obtained across the weld joint covering all three zones viz., base metal, heat affected zone and weld zone is depicted in Fig. 7. The hardness of the BM was observed to be about $440 \mathrm{HV}$ $460 \mathrm{HV}$. The maximum hardness in weld zone was $\sim 725 \mathrm{HV}$. There are many contributory factors that influence the hardness of weld zone. The peak hardness in weld zone could be associated with the strengthening effects arise due to the transformation products of retained austenite viz., martensite, high dislocation density and residual stresses. The post weld heat treatments are very critical in reducing the hardness of weld zone and retaining the parent microstructure of the base material. The heat treatment temperature could be so maintained that they should not crossover the down coiling temperature of the bainitic steel.

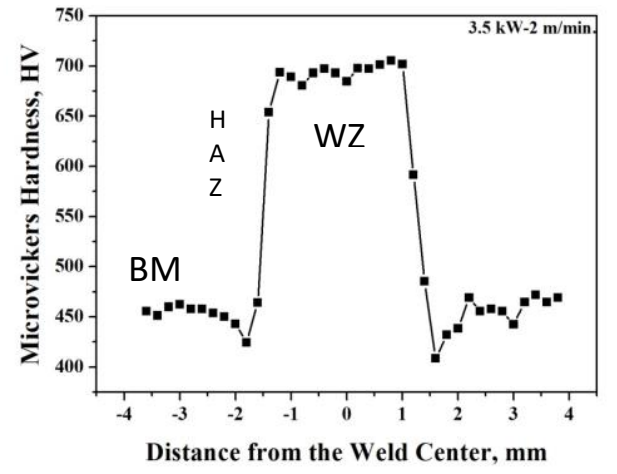

Fig. 7. Microhardness profiling across the weld joint

\subsection{Post weld heat treatments-Microscopy analysis}

FESEM images obtained on the weld zones at three different post weld heat treatment conditions are shown in Fig. 8. The base material microstructure is also indicated for the purpose of comparison. From these micrographs, it has been observed that the FESEM image of the weld zone heat treated at cycle 2 clearly shows the desired bainitic laths.
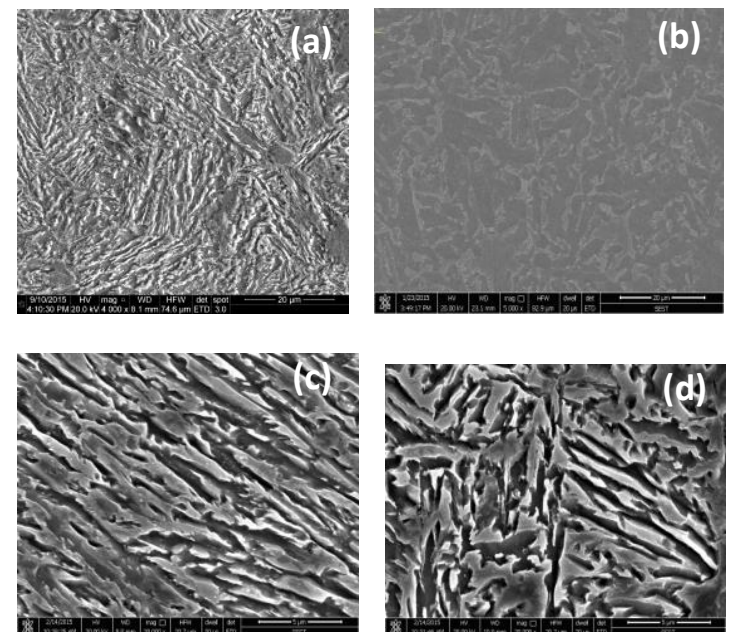

Fig. 8. FESEM images of (a) base metal and weld zones of post weld heat treated at (b) cycle 1 (c) cycle 2 , (d) cycle 3

\subsection{Microhardness profiling of PWHT conditions}

The microhardness profiles obtained from base metal to the Weld zone at all post weld heat treatment conditions are shown in Fig. 9. The microhardness profiles of the weld joint and base material are also included along with the post weld heat treated conditions. 


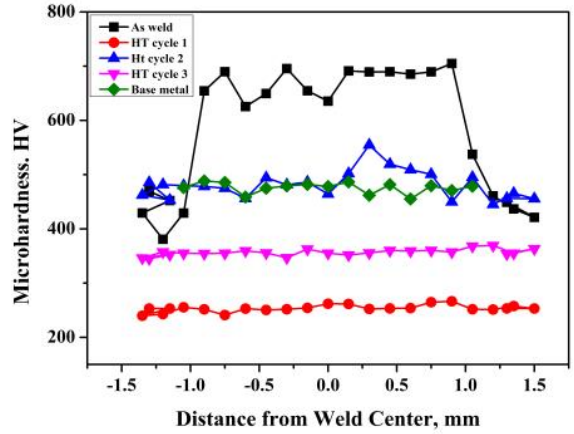

Fig. 9. Comparative microhardness profiles of all conditions (base material, as weld and as post weld heat treated)

These profiles clearly make sure that the heat treatment cycle 2 has the same profile with that of the base metal. In heat treatment cycles 1 and 3 , the hardness values of all the zones have been lesser than that of the base metal. This observation acknowledges that these cycles cannot be optimum heat treatment cycles as our objectives of retaining the parent microstructure and mechanical characteristics are not fulfilled.

\section{Summary and concluding remarks}

The bainitic steel has been subjected to Fiber Laser Welding employing a beam power of $3.5 \mathrm{~kW}$ and a speed of $2000 \mathrm{~mm} / \mathrm{min}$. Defect-free butt weld was successfully produced which ensures the feasibility of fiber laser welding for bainitic steels. The weld joint is composed of BM, HAZ, and weld zone. The microstructure was observed and microhardness profile was reported. The dendritic formation in the microstructure has been due to the rapid cooling associated with during welding. The observation of peak hardness in the weld zone accounts for the transformation to martensite. The post weld heat treatments were carried out keeping the transformation temperatures in consideration. The FESEM analysis conducted on the weld zones and microhardness profiling done at all these heat treatment conditions make it evident that optimum temperatures and soaking durations should be chosen to retain the parent microstructural features and mechanical properties. Shorter cooling times would not have permitted complete transformation to bainite. Longer soaking durations would have resulted in forming softer bainite. In either case, the hardness has been lesser than that of base metal. Optimum austenitizing and bainitic formation temperatures, and the most selective cooling time (40 min.) and soaking durations (180 min.) have lead to the formation of base metal microstructure and retention of hardness.

\section{References}

1. S. Das, A Haldar, Metallurgical and Materials Transactions A, Continuously cooled ultrafine bainitic steel with excellent strength-elongation combination, 45A, pp.1844-1854 (2014)

2. RVSM Ramakrishna, KBS Rao, GM Reddy, JP Gautam, materials today:proceedings, Friction stir welding of advanced high strength (bainitic) steels for automotive applications, 5, pp. 1713917146 (2018)

3. Z. Feng, M. Santella, S. David, R. Steel et al, SAE Technical Paper, Friction Stir Spot Welding of Advanced High-Strength Steels - A Feasibility Study, 2005-01-1248 (2005)

4. RVSM Ramakrishna, KBS Rao, GM Reddy, JP Gautam, Advanced High Strength Steel, Lecture notes in Mechanical Engineering, Recent Advances in Welding of High Strength Bainitic Steels for Automotive Applications, pp. 79-85 (2018)

5. SAA Akbari Mousavi, AR Sufizadeh, Journal of Materials and Design, Metallurgical investigations of pulsed Nd:YAG laser welding of AISI 321 and AISI 630 stainless steels, 30, pp.3150-3157, (2010)

6. RVSM. Ramakrishna, JP Gautam, G. M. Reddy, P. Masthanaiah, KBS Rao, Indian Welding Journal, Laser Welding of Ultrafine Bainitic Steels, 52, pp.52-56 (2019)

7. K. N. Krishnan, Journal of Mats. Sci. "The effect of post weld heat treatment on the properties of 6061 friction stir welded joints", 37, pp. $473-480$ (2002).

8. ASTM Standard E 384 - 99, Standard Test Method for Microindentation Hardness of Materials, ASTM INTERNATIONAL, United States of America, (2000). 